\title{
The Regulatory Roles of Ethylene and Reactive Oxygen Species (ROS) in Plant Salt Stress Responses
}

\author{
Ming Zhang ${ }^{1}$, J Andrew C Smith ${ }^{2, *}$, Nicholas P Harberd ${ }^{2, *}$, Caifu Jiang ${ }^{1, *}$ \\ ${ }^{1}$ State Key Laboratory of Plant Physiology and Biochemistry, College of Biological Sciences, China \\ Agricultural University, Beijing 100094, China. \\ ${ }^{2}$ Department of Plant Sciences, University of Oxford, South Parks Road, Oxford OX1 3RB, UK.
}

*Corresponding authors. E-mails: cfjiang@cau.edu.cn; nicholas.harberd@plants.ox.ac.uk; andrew.smith@plants.ox.ac.uk

The manuscript has $\mathbf{4 2 0 4}$ words (excluding the legend and references), with one Figure. 


\begin{abstract}
Soil salinity is one of the most commonly encountered environmental stresses affecting plant growth and crop productivity. Accordingly, plants have evolved a variety of morphological, physiological and biochemical strategies that enable them to adapt to saline growth conditions. For example, it has long been known that salinity-stress increases both the production of the gaseous stress hormone ethylene and the in planta accumulation of reactive oxygen species (ROS). Recently, there has been significant progress in understanding how the fine-tuning of ethylene biosynthesis and signaling transduction can promote salinity tolerance, and how salinity-induced ROS accumulation also acts as a signal in the mediation of salinity tolerance. Furthermore, recent advances have indicated that ethylene signaling modulates salinity responses largely via regulation of ROS-generating and ROS-scavenging mechanisms. This review focuses on these recent advances in understanding the linked roles of ethylene and ROS in salt tolerance.
\end{abstract}

\title{
Introduction
}

Soil salinity is one of the most widespread plant abiotic stresses, affecting more than $6 \%$ ( 900 million hectares) of total world land area (Tuteja 2007; Munns and Tester 2008). This salt-affected land currently includes $\sim 23 \%$ of cultivated land, and is a problem which is worsening, particularly on agricultural land where crop growth is dependent upon irrigation. Almost all of the most important crop plants are glycophytes, and are therefore sensitive to salinity (Munns and Tester 2008; Cheeseman 2015). Moderate levels of environmental salt (e.g. $100 \mathrm{mM} \mathrm{NaCl}$ ) are sufficient to cause dramatic decreases in the yield of most crops (Frommer et al. 1999; Munns and Tester 2008). High soil salinity is therefore a severe and growing problem, and is preventing the achievement of sustainable agriculture (Greenway and Munns 1980; Zhu 2002; Roy et al. 2014). There is therefore an urgent need to advance understanding of how different plants respond to salt stress, with the aim of developing crop plants better able to maintain growth and productivity on salinized lands via genetic modification or marker-assisted breeding.

Salinity-stress biology and the mechanisms of plant response to high salinity have been areas of study at physiological, biochemical, and molecular levels for many decades (Flowers et al. 1977; Greenway and Munns 1980). Plants have evolved many different strategies for tolerating high salt concentrations. In general, following the initial onset of salt stress, plants suffer two phases of stress, a rapid osmotic stress and a slower ionic stress (reviewed in Munns and Tester 2008). Accordingly, there are three major physiological adaptive mechanisms of salt tolerance: osmotic stress tolerance, maintenance of ion (especially $\mathrm{Na}^{+}$and $\mathrm{K}^{+}$) homeostasis, and compartmentalization of $\mathrm{Na}^{+}$to reduce cytosolic $\mathrm{Na}^{+}$concentrations (reviewed in Zhu 2003; Deinlein et al. 2014). Many of the components involved in the regulation of $\mathrm{Na}^{+}$and $\mathrm{K}^{+}$homeostasis have been characterized (e.g. SOSs, HKTs and NHXs; Zhu 2003; Sunarpi et al. 2005, Ji et al. 2013). However, the mechanisms of rapid osmotic phase tolerance remain poorly understood. 
It has long been known that salinity-stressed plants exhibit dramatically altered levels of many endogenous signaling molecules, including abscisic acid (ABA), ethylene, gibberellin $(G A)$, reactive oxygen species (ROS), nitric oxide (NO), and others. These signaling molecules, and their downstream signaling components, have been shown to play essential roles in salinity tolerance responses (Matsui et al. 2008; Harberd et al. 2009; León et al. 2014). For example, high environmental $\mathrm{Na}^{+}$concentrations lead to increased ABA levels and ABA signaling (Zhu 2002; Shinozaki and Dennis 2003), which in turn play vital roles in the regulation of transcriptome-level salinity responses (Xiong et al. 2001; Matsui et al. 2008). We previously found that the DELLA proteins, gibberellin-opposable growth inhibitors of the GA signaling pathway, play critical roles in plant tolerance to salt stress (reviewed in Harberd et al. 2009; Xu et al. 2014), and that salt-activated ABA and ethylene signaling pathways regulate plant growth and/or development via integration at the level of DELLA function (Achard et al. 2006). In addition, the salinity-induced reactive nitrogen species NO is an important regulator of salinity responses, and likely plays a role downstream of ABA (León et al. 2014).

Ethylene and ROS are important signaling molecules mediating numerous important biological processes, including root and root hair growth, cell fate determination, and responses to biotic and abiotic stress (Foreman et al. 2003; Apel and Hirt 2004; Chen et al. 2005; Steffens 2014). It has long been known that salinity stress increases the in planta production of ethylene and ROS. Recently, significant progress has been made in understanding the mechanism of how by which ethylene and ROS act as signaling molecules in mediating salinity tolerance, with important studies revealing that ethylene signaling modulates salinity stress response largely via regulation of ROS-generating and ROS-scavenging mechanisms (Jiang et al. 2013; Peng et al. 2014; Li et al. 2015a; Xia et al. 2015). This present review focuses on recent advances in understanding of the roles of ethylene and ROS in plant salinity response and of the crosstalk between these two classes of signaling molecules (Fig. 1).

\section{Fine-tuning of ethylene biosynthesis and ethylene signaling promotes salt tolerance}

Ethylene is often considered to be a plant stress hormone, because its synthesis is induced by various biotic and abiotic environmental stresses (Cao et al. 2007; Kazan 2015). Like many other environmental stresses, salinity promotes the production of ethylene in various species by modulating the activity of enzymes regulating ethylene biosynthesis (e.g. ACS2 and ACS7 in Arabidopsis; Achard et al. 2006; Dong et al. 2011). In addition, either endogenous overproduction of ethylene (as in the eto1 mutant) or treatment with the ethylene precursor ACC can overcome the salt-induced restraint of Arabidopsis seed germination (Divi et al. 2010). Using a soil-based mutant screen system, we previously found that, at the vegetative growth stage of the life cycle, an increase in in vivo ethylene production (as in the eto1, eto2 or eto3 mutants) promotes the salinity tolerance of Arabidopsis plants grown on saline soil when transpiration is active, but not that of plants grown in in vitro conditions where transpiration is inhibited (Jiang et al. 2013). These observations indicate that salinity-induced ethylene is a potent promoter of salt tolerance at various developmental stages and in various conditions. These ideas are 
further supported by recent studies of rice SALT TOLERANCE1 (SIT1, a lectin receptor-like kinase), which positively regulates salinity tolerance by promoting the activity of the MAPK3/6 protein kinase and promoting ethylene production (Ai et al. 2014). However, in some other cases, elevated ethylene levels can adversely affect salinity tolerance. For instance, Arabidopsis plants overexpressing wheat ACO1 display elevated ethylene levels, but decreased salinity tolerance (Chen et al. 2014). In addition, the Arabidopsisacs 7 mutant, which displays reduced ethylene production, exhibits increased salt tolerance at the seed germination stage (Dong et al. 2011). Although it has been suggested that the salinity tolerance of the acs 7 mutant might be the consequence of changed ABA sensitivity and altered transcript levels of some salinity-induced genes, the exact mechanism is yet to be understood (Dong et al. 2011). Moreover, a recent report has indicated that ethylene treatment of rice plants confers salt hypersensitivity (Yang et al. 2015). Taken together these various studies indicate that in planta ethylene levels can either negatively or positively affect the salinity sensitivity of plants, suggesting that fine-tuning of ethylene biosynthesis might be essential to salinity tolerance in plants.

Ethylene is perceived by endoplasmic reticulum-localized receptor kinases. Five ethylene receptor-encoding genes have been identified in the Arabidopsis genome: ETHYLENE RESPONSE1 (ETR1), ETR2, ETHYLENE INSENSITIVE4 (EIN4), ETHYLENE RESPONSE SENSOR1 (ERS1), and ERS2 (Hua and Meyerowitz 1998; Chen et al. 2005; Gallie 2015). Ethylene receptors negatively regulate ethylene responses, and ethylene activates downstream signaling pathways by deactivating these receptors. In essence, ethylene binds to the $\mathrm{N}$-terminal region of the ethylene receptors with the help of a copper cofactor, resulting in deactivation of a Raf-like kinase CONSTITUTIVE TRIPLE RESPONSE1 (CTR1). Deactivation of CTR1 in turn allows a C-terminal section of ETHYLENE INSENSITIVE2 (EIN2) to be cleaved and translocated into the nucleus, thus stabilizing the transcription factors ETHYLENE INSENSITIVE3 (EIN3), EIN3-like1 (EIL1) and EIL2, and consequently activating transcription of downstream targets (e.g. ethylene response factors (ERFs): reviewed in Wang et al. 2002; Guo and Ecker 2004; Zhao and Guo 2011; Ju et al. 2012; Qiao et al. 2012; Wen et al. 2012; Merchante et al. 2013; Ju and Chang 2015; Zheng and Zhu 2016). In addition, cytoplasmic EIN2 mediates ethylene signaling also via imposing the translational repression of EIN3BINDINGF-box 1 (EBF1) and EBF2 mRNA (Li et al. 2015a; Merchante et al. 2015). Accumulating evidence indicates that ethylene signaling positively regulates plant salt tolerance, including the following key observations. (1) Expression of the ETR1 gene is downregulated by salinity treatment in Arabidopsis, whilst loss of ETR1 or EIN4 function confers accelerated germination under salinity conditions (Cao et al. 2007; Wilson et al. 2014); in contrast, etr1-1, ein4-1 and etr2-1 gain-of-function mutants are insensitive to ethylene and display salt hypersensitivity compared to wild type (Cao et al. 2008). (2) Loss of CTR1 function leads to constitutive ethylene response and salt tolerance at both germination and vegetative growth stages (Achard et al. 2006; Cao et al. 2007; Jiang et al. 2013; Peng et al. 2014). (3) Loss of EIN2 function leads to delayed germination and decreased survival rate in saline conditions (Wang et al. 2007; Peng et al. 2014), suggesting that EIN2 positively regulates salt tolerance; further studies have indicated that EIN2 positively regulates salt tolerance not only by affecting the level of the 
EIN3 protein (Peng et al. 2014), but also by negatively regulating ABA synthesis or through physical interaction with an MA3 domain-containing protein (ECIP1, a positive regulator of salt tolerance) (Ghassemian et al. 2000; Wang et al. 2007; Lei et al. 2011). (4) A recent report indicates that salinity leads to accumulation of the EIN3 protein via both EIN2-dependent and EIN2-independent pathways and by promoting the degradation of the F-box protein EBF1 and EBF2, suggesting that salinity-induced accumulation of EIN3 confers salt tolerance (Peng et al. 2014); this is supported by genetic evidence showing that overexpression of EIN3 promotes salinity tolerance, whilst loss of EIN3 function confers salinity sensitivity in Arabidopsis (Peng et al. 2014). (5) It has been repeatedly confirmed that overexpression of EIN3 target genes (e.g. ERFs and SALT-INDUCED EIN3/EIL1-DEPENDENT1 (SIED1)) in various species leads to salt tolerance (Zhang et al. 2004; Zhang et al. 2011; Cheng et al. 2013; Imen et al. 2014). (6) Salinity induces transcriptional changes of many genes in an EIN3/EIL1-dependent manner (Peng et al. 2014). All of the above evidence indicates that salinity can lead to enhanced ethylene signaling (e.g. by stabilizing EIN3 and EIL1), which in turn can act as a potent promoter of salt tolerance. However, Yang et al. (2015) in contrast found that overexpression OSEIL1 and OsEIL2, rice homologs of EIN3, causes salt hypersensitivity at the seedling stage, whilst loss of OsEIL1 and OsEIL2 function promotes salt tolerance, suggesting that EIN3-dependent ethylene signaling negatively, rather than positively, affects salinity tolerance in rice, at least at the seedling stage.

\section{ROS homeostasis is essential for the ethylene regulation of salt tolerance}

Reactive oxygen species (ROS), such as ${ }^{1} \mathrm{O}_{2}, \mathrm{H}_{2} \mathrm{O}_{2}, \mathrm{O}_{2}{ }^{-}$and $\mathrm{HO}$, are highly reactive molecules, capable of causing oxidative damage to protein, DNA and lipids (Apel and Hirt 2004; Miller et al. 2010). However, as well as being toxic molecules, ROS also act as important signaling molecules regulating many important biological processes, such as growth, development, and responses to abiotic and biotic stresses (Foreman et al. 2003; Miller et al. 2008). Because ROS play a dual role in plants, ROS synthesis and ROS scavenging machineries are tightly regulated to achieve appropriate levels of ROS at different developmental stages and in different growing environments (Foreman et al. 2003; Jayakumar et al. 2014). It has long been known that, in abiotic and biotic stress conditions, the levels of ROS in plant tissues can be dramatically elevated. In particular, salinity stress causes elevated ROS levels, and these elevated ROS levels play a dual role in the salinity responses of plants: (1) ROS act as toxic byproducts causing oxidative damage; (2) ROS act as signaling molecules mediating salt tolerance (Chung et al. 2008; Miller et al. 2008; Ma et al. 2012; Jiang et al. 2013). Because the oxidative damage aspects of salinity-stress induced ROS have already been extensively reviewed (Miller et al. 2010; Mittler et al. 2011; Steinhorst and Kudla 2014), we here focus on the signaling roles of ROS, with special focus on its roles in ethylene-dependent salinity tolerance mechanisms.

Previous studies have shown that a variety of ethylene-regulated biological processes are associated with the regulation of ROS homeostasis (Wilkinson and Davies 2009; He et al. 2011; Jiang et al. 2013; Peng et al. 2014; Xia et al. 2015). For example, ethylene promotes tolerance to potassium deprivation by promoting ROS production (Jung et 
al. 2009; Schachtman 2015). Also, ethylene mediates UV-B- and ozone-induced stomatal closure through peroxidase-dependent $\mathrm{H}_{2} \mathrm{O}_{2}$ synthesis in Vicia faba (Wilkinson and Davies 2009; He et al. 2011). We previously found that the soil-salinity sensitive1-1 (sss1-1) mutant of Arabidopsis displays a salt hypersensitivity phenotype due to loss-of-function of AtrbohF (one member of a family of ten NADPH oxidases in Arabidopsis that catalyze production of ROS) and the consequent absence of salinity-induced ROS accumulation in root vasculature, suggesting that AtrbohF confers salinity-induced vasculature-specific ROS accumulation and salinity tolerance (Jiang et al. 2012). Moreover, we found that, whilst an increase in ethylene production (e.g. in eto1) or constitutive activation of ethylene signaling (e.g. in ctr1) leads to increased accumulation of ROS in root vascular tissue and increased salt tolerance, eto1 atrbohf and ctr1 atrbohf double mutants both lack salinity-induced ROS accumulation and are hypersensitive to salinity stress (with a sensitivity similar to that of the atrbohf single mutant). In addition, we found that ethylene signaling positively regulates the levels of transcripts encoding AtrbohF in root vasculature via the ETR1-CTR1-dependent signaling pathway, suggesting that ethylene signaling promotes salt tolerance by enhancing tissue-specific, AtrbohF-dependent ROS biosynthesis in root vasculature tissue (Jiang et al. 2013). Intriguingly, another study indicated that ethylene affects stomatal aperture also through regulation of AtrbohF-dependent ROS production in guard cells (Desikan et al. 2006). These studies thus indicate that AtrbohF-dependent ROS production may be an important downstream mediator of ethylene signaling cascades. The idea that ethylene promotes salinity tolerance by increasing ROS production is further supported by studies of the rice receptor-like kinase SIT1. The SIT1 protein resides on the plasma membrane, and its kinase activity is rapidly activated by salinity stress, causing activation of MPK3/6, in turn promoting ethylene synthesis and ROS production, and hence increasing the salt tolerance of rice (Ai et al. 2014).

In addition to ethylene, $\mathrm{ABA}$ and $\mathrm{JA}$ treatments also induce stomatal closure via AtrbohFand AtrbohD- dependent mechanisms (Kwak et al. 2003; Suhita et al. 2004), and there are reports indicating the interconnection of ethylene, JA and $A B A$ in the regulation of stomatal closure. For example, ethylene treatment inhibits $A B A$-induced stomatal closure (Tanaka et al. 2015), and ost1 (an ABA-insensitive mutant) displays compromised JA-induced stomatal closure (Suhita et al. 2004), whilst jar1 (a JA-insensitive mutant) exhibits diminished ABA-induced stomatal closure (Suhita et al. 2004). Nevertheless, the overall relationships between ethylene-, JA- and ABA-regulated stomatal closure remain largely unknown (Murata et al. 2015).

As shown above, ethylene in many cases positively regulates the biosynthesis of ROS. However, there are also alternative cases in which ethylene appears to negatively regulate ROS production in specific circumstances. For example, overexpression of JERF3, an ERF protein, enhances tolerance to salt, drought, and freezing in tobacco seedlings by reducing ROS accumulation (Wu et al. 2008). In addition, a recent study indicated that salinity-induced accumulation of EIN3/EIL1 promotes salinity tolerance, likely by enhancing ROS scavenging at the seedling stage in Petri-dish conditions (Peng et al. 2014). 
This study showed that EIN3/EIL1 regulates transcriptional change of over 200 genes under salinity conditions: 92 salt-induced EIN3/EIL1-dependent (SIED) genes and 121 salt-repressed EIN3/EIL1-dependent (SRED) genes were found. Genes encoding oxidoreductases were found to be enriched in SIED, whilst many genes encoding peroxidases (PODs) were found to be induced by salt treatment via an EIN3/EIL1-dependent mechanism. Accordingly, an ein3 eil1 double mutant displayed lower levels of POD-encoding transcripts, higher levels of ROS, and consequent hypersensitivity to salt stress (Peng et al. 2014). These results thus suggest an alternative mechanism to explain how EIN3 promotes salt tolerance, namely by enhancing the scavenging of toxic ROS.

The ROS steady-state is regulated by a complex network comprising more than a hundred genes (Mittler et al. 2004). It is therefore not surprising to find that ethylene promotes both ROS synthesis and scavenging at different developmental stages, under different growth conditions, and in different tissues following the onset of salinity treatments (Jiang et al. 2013; Peng et al. 2014). In addition, ethylene-dependent salinity tolerance mechanisms have been shown to have wide-ranging crosstalk with other salt tolerance pathways (Xia et al. 2015). It is therefore possible that under different experimental conditions, and at different developmental stages, ethylene signaling interacts preferentially with different pathways and thus differentially regulates ROS synthesis and scavenging mechanisms. However, the exact mechanisms for these differential preferences is yet to be understood.

Ethylene signaling regulates $\mathrm{Na}^{+} / \mathrm{K}^{+}$homeostasis via ROS-dependent and ROS-independent mechanisms

High soil sodium ion $\left(\mathrm{Na}^{+}\right)$concentrations cause inhibition of $\mathrm{K}^{+}$uptake, increased loss of $\mathrm{K}^{+}$, and an increase in $\mathrm{Na}^{+}$uptake, thus leading to a decrease in plant $\mathrm{K}^{+} / \mathrm{Na}^{+}$ratio (Zhu 2003; Shabala and Cuin 2008). It has long been known that maintenance of $\mathrm{Na}^{+} / \mathrm{K}^{+}$homeostasis is essential for soil-salinity tolerance. A variety of mechanisms contributing to maintenance of $\mathrm{Na}^{+} / \mathrm{K}^{+}$homeostasis in high salinity conditions have been characterized, including: reduced net $\mathrm{Na}^{+}$uptake into the root (i.e. decreased $\mathrm{Na}^{+}$influx and/or increased $\mathrm{Na}^{+}$efflux) and reduced xylem loading (Zhu 2003); retrieval of $\mathrm{Na}^{+}$from the transpiration stream xylem sap during transport to the shoot (Sunarpi et al. 2005; Munns and Tester 2008); sequestration of $\mathrm{Na}^{+}$into vacuoles to avert ion toxicity in the cytosol (Amtmann and Sanders 1999); and excretion of excess $\mathrm{Na}^{+}$by the salt glands characteristic of some halophytic plants (Smith et al. 2010). Among the best understood of the mechanisms regulating $\mathrm{Na}^{+}$homeostasis are the SALT OVERLY SENSITIVE1 (SOS1) (Shi et al. 2000; Qiu et al. 2002; Lin et al. 2009; Zhou et al. 2015; reviewed in Zhu 2003 and Ji et al. 2013) and HIGH-AFFINITY K+ TRANSPORTER1 (HKT1) HKT1 pathways (Mäser et al. 2002; Sunarpi et al. 2005). Either tissue-specific (e.g. vasculature-specific) overexpression of AtHKT1 or ectopic overexpression of AtSOS1 causes reduced shoot $\mathrm{Na}^{+}$accumulation, thus lowering the $\mathrm{Na}^{+} / \mathrm{K}^{+}$ratio and in turn promoting the salinity tolerance of $A$. thaliana (Schachtman and Schroeder 1994; Shi et al. 2000; Møller et al. 2009; Yang et al. 2009; reviewed in Zhu 2002 and Horie et al. 2009). 
Previous studies have indicated that ROS likely play important roles in the regulation of $\mathrm{Na}^{+}$and $\mathrm{K}^{+}$homeostasis (Apel and Hirt 2004; Miller et al. 2010; Mittler et al. 2011). For example, studies of poplar callus cells indicated that salinity-induced production of $\mathrm{H}_{2} \mathrm{O}_{2}$ promotes salt tolerance by maintaining reduced $\mathrm{Na}^{+}$and increased $\mathrm{K}^{+}$levels, thus lowering the $\mathrm{Na}^{+} / \mathrm{K}^{+}$ratio (Zhang et al. 2007; Sun et al. 2010). Ma et al. (2012) found that, under in vitro conditions, the atrbohdatrbohf double mutant, but not

the atrbohd or atrbohf single mutants, exhibit overaccumulation of $\mathrm{Na}^{+}$in saline conditions. This overaccumulation of $\mathrm{Na}^{+}$adversely affects $\mathrm{K}^{+}$influx, suggesting that AtrbohD and AtrbohF redundantly regulate $\mathrm{Na}^{+} / \mathrm{K}^{+}$homeostasis (at least under the particular conditions used in this study). Ma et al. (2012) also showed that atrbohdatrbohf displays reduced $\mathrm{K}^{+}$influx not only in saline conditions, but also in control (non-saline) conditions, suggesting that ROS produced by AtrbohD and AtrbohF is essential for the regulation of $\mathrm{K}^{+}$homeostasis. In contrast, we recently showed that AtrbohF alone confers essential regulation of $\mathrm{Na}^{+}$homeostasis and salt tolerance in plants grown in soil (Jiang et al. 2012). We found that the salinity-induced, AtrbohF-mediated increase in root vascular ROS levels restricts xylem-sap $\mathrm{Na}^{+}$content, thus reducing transport of $\mathrm{Na}^{+}$from root to the shoot, resulting in a reduced $\mathrm{Na}^{+} / \mathrm{K}^{+}$ratio and contributing to soil-salinity tolerance (Jiang et al. 2012). Despite the wealth of evidence indicating that salinity-induced ROS production confers regulation of $\mathrm{Na}^{+}$and $\mathrm{K}^{+}$homeostasis, the exact molecular mechanism of this regulation remains largely unknown. One possible mechanism is that ROS regulate $\mathrm{Na}^{+}$and $\mathrm{K}^{+}$homeostasis by regulating the activity of $\mathrm{PM} \mathrm{Ca}^{2+}$-permeable channels, which in turn regulate the activity of downstream components such as MPKs, SOS2 and other CBLs (Mori and

Schroeder 2004; Pottosin et al. 2014). This possibility is attractive because ROS regulation of cytosolic free $\mathrm{Ca}^{2+}$ concentrations are known to play important roles in regulating root hair growth and in long-distance signal propagation (Foreman et al. 2003; Steinhorst and Kudla 2014). Alternatively, ROS may regulate $\mathrm{Na}^{+}$and $\mathrm{K}^{+}$homeostasis via effects on the stability of SOS1 (Salt Overly Sensitive 1, encoding the $\mathrm{PM} \mathrm{Na}{ }^{+} / \mathrm{H}^{+}$anti-porter) mRNA and on the activity of the PM H+-ATPase (Zhang et al. 2007; Chung et al. 2008; Ma et al. 2012).

Ethylene has also been shown to play important roles in the regulation of $\mathrm{Na}^{+}$and $\mathrm{K}^{+}$homeostasis. Yang et al. (2013) showed that ethylene can facilitate the retention of $\mathrm{K}^{+}$in saline conditions. Our recent study found that, following onset of salinity treatment, and in conditions where transpiration is active, ETR1-CTR1 dependent ethylene signaling not only promotes $\mathrm{K}^{+}$retention, but also significantly contributes to inhibition of root-to-shoot $\mathrm{Na}^{+}$delivery by regulating AtrbohF-dependent vasculature-specific ROS production (Jiang et al. 2013). This finding provides genetic evidence that AtrbohF-ROS regulation of $\mathrm{Na}^{+}$homeostasis acts downstream of ethylene signaling. Intriguingly, we also found in contrast that ethylene promotes the retention of $\mathrm{K}^{+}$via an AtrbohF-independent mechanism, possibly via increase in the level of transcripts encoding AtHAK5 (a high-affinity $\mathrm{K}^{+}$transporter) in saline conditions. Because ethylene can increase AtHAK5 transcript levels in either low $\mathrm{K}^{+}$or high Fe stress conditions (Jung et al. 2009; Li et al. 2015b), and because the effect of low $\mathrm{K}^{+}$on levels of transcripts encoding AtHAK5 is AtrbohC-dependent (Shin and Schachtman 2004), it is possible that ethylene 
promotes the retention of $\mathrm{K}^{+}$in saline conditions via a mechanism dependent upon the function of another NADPH oxidase (i.e. AtrbohC rather than AtrbohF). However, this possibility requires further experimental verification.

\section{Conclusions and perspectives}

There has recently been significant progress in our understanding of the roles of ethylene and ROS in plant salinity responses, and of how ethylene and ROS interact with one another to regulate salt tolerance. Nevertheless, many questions remain unanswered, amongst which are the following. (1) Although the majority of the studies reviewed above suggest that increased levels of ethylene and associated activation of the ethylene signaling pathway are positively associated with salinity tolerance, there are instances where such increases, at particular developmental stages, or under particular experimental or environmental conditions, or in different species, are suggested to negatively affect salinity tolerance. The molecular basis of these cases of negative association remain largely unknown. (2) Current knowledge suggests that ethylene promotes salinity tolerance either by enhancing ROS scavenging (thus attenuating oxidative damage) or by promoting root-vasculature-specific accumulation of ROS (thus enhancing $\mathrm{Na}^{+} / \mathrm{K}^{+}$homeostasis). Nevertheless, the precise molecular mechanisms by which ethylene tunes the ROS scavenging and ROS generating machinery to maintain proper ROS levels in different tissue and cellular compartments remains unclear. (3) The activity of AtrbohF is regulated at both transcriptional and posttranscriptional levels. Although previous reports have indicated that ethylene positively regulates AtrbohF transcript levels, it remains unclear if ethylene affects the activity of AtrbohF at the posttranscriptional level, for example, by regulating the protein kinases (e.g. OST1 and CIPK26) that directly phosphorylate and regulate the activity of AtrbohF (Sirichandra et al. 2009; Kimura et al. 2013). (4) It has been suggested that elevated ROS can cause increased cytosolic free $\mathrm{Ca}^{2+}$ concentrations, which in turn can lead to a reduced $\mathrm{Na}^{+} / \mathrm{K}^{+}$ratio. Meanwhile, the ROS produced by AtrbohF has been shown to play an important role in the regulation of $\mathrm{Na}^{+} / \mathrm{K}^{+}$homeostasis and salt tolerance. Further work is needed to determine if AtrbohF-produced ROS enhances the $\mathrm{Na}^{+} / \mathrm{K}^{+}$ratio by $\mathrm{Ca}^{2+}$-dependent mechanisms. (5) Like other stress signals, salinity results in the enhanced production of ROS that act as signaling molecules to trigger acclimation responses. In the future, the application and development of new cellular imaging and real-time detection tools will advance our understanding of the tissue- and cell-specificity of salinity-induced ROS responses. Such studies will further advance our understanding of the roles of ethylene and ROS in salt tolerance, and will potentially provide new routes towards the development of salt-tolerant crops.

\section{Acknowledgments}

The authors acknowledge financial support from the Chinese Universities Scientific Fund (Grant 2014RC021 to C.J.); the National Natural Science Foundation of China (Grant 31470350 to C.J.); and the UK Biotechnological and Biological Sciences Research Council (Grant BB/F020759/1 to N.P.H.). 


\section{References}

1. Achard P, Cheng H, De Grauwe L, Decat J, Schoutteten H, Moritz T, Van Der Straeten D, Peng J, Harberd NP (2006) Integration of plant responses to environmentally activated phytohormonal signals. Science 311:91-94

2. Ai LF, Li CH, Wang G, Zhao JL, Zhang LQ, Han YF, Sun DY, Zhang SW, Sun Y (2014) The receptor-like kinase SIT1 mediates salt sensitivity by activating MAPK3/6 and regulating ethylene homeostasis in rice. Plant Cell 26:2538-2553

3. Amtmann A, Sanders D (1999) Mechanisms of $\mathrm{Na}^{+}$uptake by plant cells. Adv Bot Res 29:75-112

4. Apel K, Hirt H (2004) Reactive oxygen species: metabolism, oxidative stress, and signal transduction. Annu Rev Plant Biol 55:373-399

5. Cao WH, Liu J, He XJ, Mu RL, Zhou HL, Chen SY, Zhang JS (2007) Modulation of ethylene responses affects plant salt-stress responses. Plant Physiol 143:707-719

6. Cao YR, Chen SY, Zhang JS (2008) Ethylene signaling regulates salt stress response. Plant Signal Behav 3:761-763

7. Cheeseman JM (2015) The evolution of halophytes, glycophytes and crops, and its implications for food security under saline conditions. New Phytol 206:557-570

8. Chen YF, Etheridge N, Schaller GE (2005) Ethylene signal transduction. Ann Bot 95:901-915

9. Chen D, Ma X, Li C, Zhang W, Xia G, Wang M (2014) A wheat aminocyclopropane-1-carboxylate oxidase gene, TaACO1, negatively regulates salinity stress in Arabidopsis thaliana. Plant Cell Rep 33:1815-1827

10. Cheng MC, Liao PM, Kuo WW, Lin TP (2013) The Arabidopsis ETHYLENE RESPONSE FACTOR1 regulates abiotic stress-responsive gene expression by binding to different cis-acting elements in response to different stress signals. Plant Physiol 162:1566-1582

11. Chung JS, Zhu JK, Bressan RA, Hasegawa PM, Shi HZ (2008) Reactive oxygen species mediate $\mathrm{Na}^{+}$-induced SOS1 mRNA stability in Arabidopsis. Plant J 53:554-565

12. Deinlein U, Stephan AB, Horie T, Luo W, Xu G, Schroeder JI (2014) Plant salt-tolerance mechanisms. Trends Plant Sci 19:371-379

13. Desikan R, Last K, Harrett-Williams R, Tagliavia C, Harter K, Hooley R, Hancock JT, Neill SJ (2006) Ethylene-induced stomatal closure in Arabidopsis occurs via AtrbohF-mediated hydrogen peroxide synthesis. Plant J 47:907-916

14. Divi UK, Rahman T, Krishna P (2010) Brassinosteroid-mediated stress tolerance in Arabidopsis shows interactions with abscisic acid, ethylene and salicylic acid pathways. BMC Plant Biol 10:151 
15. Dong H, Zhen Z, Peng J, Chang L, Gong Q, Wang NN (2011) Loss of ACS7 confers abiotic stress tolerance by modulating ABA sensitivity and accumulation in Arabidopsis. J Exp Bot 62:48754887

16. Flowers TJ, Troke PF, Yeo AR (1977) The mechanism of salt tolerance in halophytes. Ann Rev Plant Physiol 28:89-121

17. Foreman J, Demidchik V, Bothwell JH, Mylona P, Miedema H, Torres MA, Linstead P, Costa S, Brownlee C, Jones JD, Davies JM, Dolan L (2003) Reactive oxygen species produced by NADPH oxidase regulate plant cell growth. Nature 422:442-446

18. Frommer WB, Ludewig U, Rentsch D (1999) Taking transgenic plants with a pinch of salt. Science 285:1222-1223

19. Gallie DR (2015) Appearance and elaboration of the ethylene receptor family during land plant evolution. Plant Mol Biol 87:521-539

20. Ghassemian M, Nambara E, Cutler S, Kawaide H, Kamiya Y, McCourt P (2000) Regulation of abscisic acid signaling by the ethylene response pathway in Arabidopsis. Plant Cell 12:1117-1126

21. Greenway H, Munns RA (1980) Mechanisms of salt tolerance in non-halophytes. Annu Rev Plant Physiol 31:149-190

22. Guo H, Ecker JR (2004) The ethylene signaling pathway: new insights. Curr Opin Plant Biol 7:4049

23. Harberd NP, Belfield E, Yasumura Y (2009) The angiosperm gibberellin-GID1-DELLA growth regulatory mechanism: how an "inhibitor of an inhibitor" enables flexible response to fluctuating environments. Plant Cell 21:1328-1339

24. He J, Yue X, Wang R, Zhang Y (2011) Ethylene mediates UV-B-induced stomatal closure via peroxidase-dependent hydrogen peroxide synthesis in Vicia faba L. J Exp Bot 62:2657-2666

25. Horie T, Hauser F, Schroeder JI (2009) HKT transporter-mediated salinity resistance mechanisms in Arabidopsis and monocot crop plants. Trends Plant Sci 14:660-668

26. Hua J, Meyerowitz EM (1998) Ethylene responses are negatively regulated by a receptor gene family in Arabidopsis thaliana. Cell 94:261-271

27. Imen K, Pirrello J, Riahi L, Bernadac A, Cherif A, Bouzayen M, Bouzid S (2014) Ethylene response factor SI-ERF.B. 3 is responsive to abiotic stresses and mediates salt and cold stress response regulation in tomato. Sci World J 2014:1-12

28. Jayakumar B, Ana RM, Shabala S (2014) ROS homeostasis in halophytes in the context of salinity stress tolerance. J Exp Bot 65:1241-1257

29. Ji H, Pardo JM, Batelli G, Van Oosten MJ, Bressan RA, Li X (2013) The salt overly sensitive (SOS) pathway: established and emerging roles. Mol Plant 6:275-286 
30. Jiang C, Belfield EJ, Mithani A, Visscher A, Ragoussis J, Mott R, Smith JAC, Harberd NP (2012) ROS-mediated vascular homeostatic control of root-to-shoot soil Na delivery in Arabidopsis. EMBO J 31:4359-4370

31. Jiang C, Belfield EJ, Cao Y, Smith JAC, Harberd NP (2013) An Arabidopsis soil salinity-tolerance mutation confers ethylene-mediated enhancement of sodium/potassium homeostasis. Plant Cell 25:3535-3552

32. Ju C, Chang C (2015) Mechanistic insights in ethylene perception and signal transduction. Plant Physiol 169:85-95

33. Ju C, Yoon GM, Shemansky JM, Lin DY, Ying ZI, Chang J, Garrett WM, Kessenbrock M, Groth G, Tucker ML, Cooper B, Kieber JJ, Chang C (2012) CTR1 phosphorylates the central regulator EIN2 to control ethylene hormone signaling from the ER membrane to the nucleus in Arabidopsis. Proc Natl Acad Sci USA 109:19486-19491

34. Jung JY, Shin R, Schachtman DP (2009) Ethylene mediates response and tolerance to potassium deprivation in Arabidopsis. Plant Cell 21:607-621

35. Kazan K (2015) Diverse roles of jasmonates and ethylene in abiotic stress tolerance. Trends Plant Sci 20:219-229

36. Kimura S, Kawarazaki T, Nibori H, Michikawa M, Imai A, Kaya H, Kuchitsu K (2013) The CBL-interacting protein kinase CIPK26 is a novel interactor of Arabidopsis NADPH oxidase AtRbohF that negatively modulates its ROS-producing activity in a heterologous expression system. J Biochem 153:191-195

37. Kwak JM, Mori IC, Pei ZM, Leonhardt N, Torres MA, Dangl JL, Bloom RE, Bodde S, Jones JD, Schroeder JI (2003) NADPH oxidase AtrbohD and AtrbohF genes function in ROS-dependent ABA signaling in Arabidopsis. EMBO J 22:2623-2633

38. Lei G, Shen M, Li ZG, Zhang B, Duan KX, Wang N, Cao YR, Zhang WK, Ma B, Ling HQ, Chen SY, Zhang JS (2011) EIN2 regulates salt stress response and interacts with a MA3 domain-containing protein ECIP1 in Arabidopsis. Plant Cell Environ 34:1678-1692

39. León J, Castillo MC, Coego A, Lozano-Juste J, Mir R (2014) Diverse functional interactions between nitric oxide and abscisic acid in plant development and responses to stress. J Exp Bot 65:907-921

40. Li W, Ma M, Feng Y, Li H, Wang Y, Ma Y, Li M, An F, Guo H (2015a) EIN2-directed translational regulation of ethylene signaling in Arabidopsis. Cell 163:670-683

41. Li G, Xu W, Kronzucker HJ, Shi W (2015b) Ethylene is critical to the maintenance of primary root growth and Fe homeostasis under Fe stress in Arabidopsis. J Exp Bot 66:2041-2054

42. Lin H, Yang Y, Quan R, Mendoza I, Wu Y, Du W, Zhao S, Schumaker KS, Pardo JM, Guo Y (2009) Phosphorylation of SOS3-LIKE CALCIUM BINDING PROTEIN8 by SOS2 protein kinase stabilizes their protein complex and regulates salt tolerance in Arabidopsis. Plant Cell 21:1607-1619 
43. Ma L, Zhang $\mathrm{H}$, Sun L, Jiao $Y$, Zhang $G$, Miao $C$, Hao F (2012) NADPH oxidase AtrbohD and AtrbohF function in ROS-dependent regulation of $\mathrm{Na}^{+} / \mathrm{K}^{+}$homeostasis in Arabidopsis under salt stress. J Exp Bot 63:305-317

44. Mäser P, Eckelman B, Vaidyanathan R, Horie T, Fairbairn DJ, Kubo M, Yamagami M, Yamaguchi $K$, Nishimura M, Uozumi N, Robertson W, Sussman MR, Schroeder JI (2002) Altered shoot/root $\mathrm{Na}^{+}$distribution and bifurcating salt sensitivity in Arabidopsis by genetic disruption of the $\mathrm{Na}^{+}$transporter AtHKT1. FEBS Lett 531:157-161

45. Matsui A, Ishida J, Morosawa T, Mochizuki Y, Kaminuma E, Endo TA, Okamoto M, Nambara E, Nakajima M, Kawashima M, Satou M, Kim JM, Kobayashi N, Toyoda T, Shinozaki K, Seki M (2008) Arabidopsis transcriptome analysis under drought, cold, high-salinity and ABA treatment conditions using a tiling array. Plant Cell Physiol 49:1135-1149

46. Merchante C, Alonso JM, Stepanova AN (2013) Ethylene signaling: simple ligand, complex regulation. Curr Opin Plant Biol 16:554-560

47. Merchante C, Brumos J, Yun J, Hu Q, Spencer KR, Enríquez P, Binder BM, Heber S, Stepanova AN, Alonso JM (2015) Gene-specific translation regulation mediated by the hormone-signaling molecule EIN2. Cell 163:684-697

48. Miller G, Shulaev V, Mittler R (2008) Reactive oxygen signaling and abiotic stress. Physiol Plant 133:481-489

49. Miller G, Suzuki N, Ciftci-Yilmaz S, Mittler R (2010) Reactive oxygen species homeostasis and signalling during drought and salinity stresses. Plant Cell Environ 33:453-467

50. Mittler R, Vanderauwera S, Gollery M, Van BF (2004) Reactive oxygen gene network of plants. Trends Plant Sci 9:490-498

51. Mittler R, Vanderauwera S, Suzuki N, Miller G, Tognetti VB, Vandepoele K, Gollery M, Shulaev V, Van Breusegem F (2011) ROS signaling: The new wave? Trends Plant Sci 16:300-309

52. Møller IS, Gilliham M, Jha D, Mayo GM, Roy SJ, Coates JC, Haseloff J, Tester M (2009) Shoot $\mathrm{Na}^{+}$exclusion and increased salinity tolerance engineered by cell type-specific alteration of Nattransport in Arabidopsis. Plant Cell 21:2163-2178

53. Mori IC, Schroeder JI (2004) Reactive oxygen species activation of plant $\mathrm{Ca}^{2+}$ channels. A signaling mechanism in polar growth, hormone transduction, stress signaling, and hypothetically mechanotransduction. Plant Physiol 135:702-708Munns R, Tester M (2008) Mechanisms of salinity tolerance. Annu Rev Plant Biol 59:651-681

54. Murata Y, Mori IC, Munemasa S (2015) Diverse stomatal signaling and the signal integration mechanism. Annu Rev Plant Biol 66:369-392

55. Peng J, Li Z, Wen X, Li W, Shi H, Yang L, Zhu H, Guo H (2014) Salt-induced stabilization of EIN3/EIL1 confers salinity tolerance by deterring ROS accumulation in Arabidopsis. PLoS Genet 10:e1004664 
56. Pottosin I, Buendía AMV, Bose J, Jazo IZ, Shabala S, Dobrovinskaya O (2014) Cross-talk between reactive oxygen species and polyamines in regulation of ion transport across the plasma membrane: implications for plant adaptive responses. J Exp Bot 65:1271-1283

57. Qiao H, Shen Z, Huang SS, Schmitz RJ, Urich MA, Briggs SP, Ecker JR (2012) Processing and subcellular trafficking of ER-tethered EIN2 control response to ethylene gas. Science 338:390-393

58. Qiu QS, Guo Y, Dietrich MA, Schumaker KS, Zhu JK (2002) Regulation of SOS1, a plasma membrane $\mathrm{Na}^{+} / \mathrm{H}^{+}$exchanger in Arabidopsis thaliana, by SOS2 and SOS3. Proc Natl Acad Sci USA 99:8436-8441

59. Roy SJ, Negrão S, Tester M (2014) Salt resistant crop plants. Curr Opin Biotechnol 26:115-124

60. Schachtman DP (2015) The role of ethylene in plant responses to $\mathrm{K}^{+}$deficiency. Front Plant Sci 6:1153

61. Schachtman DP, Schroeder JI (1994) Structure and transport mechanism of a high-affinity potassium uptake transporter from higher plants. Nature 370:655-658

62. Shabala S, Cuin TA (2008) Potassium transport and plant salt tolerance. Physiol Plant 133:651669

63. Shi H, Ishitani M, Kim C, Zhu JK (2000) The Arabidopsis thaliana salt tolerance gene SOS1 encodes a putative $\mathrm{Na}^{+} / \mathrm{H}^{+}$antiporter. Proc Natl Acad Sci USA 97:6896-6901 Central

64. Shin R, Schachtman DP (2004) Hydrogen peroxide mediates plant root cell response to nutrient deprivation. Proc Natl Acad Sci USA 101:8827-8832Central

65. Shinozaki K, Dennis ES (2003) Cell signalling and gene regulation: global analyses of signal transduction and gene expression profiles. Curr Opin Plant Biol 6:405-409

66. Sirichandra C, Gu D, Hu HC, Davanture M, Lee S, Djaoui M, Valot B, Zivy M, Leung J, Merlot S, Kwak JM (2009) Phosphorylation of the Arabidopsis AtrbohF NADPH oxidase by OST1 protein kinase. FEBS Lett 583:2982-2986

67. Smith AM, Coupland G, Dolan L, Harberd N, Jones J, Martin C, Sablowski R, Amey A (2010) Plant biology. USA Garland Science, Taylor \& Francis Group, LLC, New York

68. Steffens B (2014) The role of ethylene and ROS in salinity, heavy metal, and flooding. Front Plant Sci 5:685Central

69. Steinhorst L, Kudla J (2014) Signaling in cells and organisms-calcium holds the line. Curr Opin Plant Biol 22:14-21

70. Suhita D, Raghavendra AS, Kwak JM, Vavasseur A (2004) Cytoplasmic alkalization precedes reactive oxygen species production during methyl jasmonate- and abscisic acid-induced stomatal closure. Plant Physiol 134:1536-1545Central 
71. Sun J, Wang MJ, Ding MQ, Deng SR, Liu MQ, Lu CF, Zhou XY, Shen X, Zheng XJ, Zhang ZK, Song J, $\mathrm{Hu} Z \mathrm{ZM}, \mathrm{Xu}$ Y, Chen SL (2010) $\mathrm{H}_{2} \mathrm{O}_{2}$ and cytosolic $\mathrm{Ca}^{2+}$ signals triggered by the $\mathrm{PM} \mathrm{H}^{+}$-coupled transport system mediate $\mathrm{K}^{+} / \mathrm{Na}^{+}$homeostasis in $\mathrm{NaCl}$-stressed Populus euphratica cells. Plant Cell Environ 33:943-958

72. Sunarpi Horie T, Motoda J, Kubo M, Yang H, Yoda K, Horie R, Chan WY, Leung HY, Hattori K, Konomi M, Osumi M, Yamagami M, Schroeder JI, Uozumi N (2005) Enhanced salt tolerance mediated by AtHKT1 transporter-induced Na unloading from xylem vessels to xylem parenchyma cells. Plant J 44:928-938

73. Tanaka Y, Sano T, Tamaoki M, Nakajima N, Kondo N, Hasezawa S (2015) Ethylene inhibits abscisic acid-induced stomatal closure in Arabidopsis. Plant Physiol 138:2337-2343

74. Tuteja N (2007) Mechanisms of high salinity tolerance in plants. Method Enzymol 428:419-438

75. Wang KL, Li H, Ecker JR (2002) Ethylene biosynthesis and signaling networks. Plant Cell 14(Suppl 1):S131-S151 Central

76. Wang Y, Liu C, Li K, Sun F, Hu H, Li X, Zhao Y, Han C, Zhang W, Duan Y, Liu M, Li X (2007) Arabidopsis EIN2 modulates stress response through abscisic acid response pathway. Plant Mol Biol 64:633-644

77. Wen X, Zhang C, Ji Y, Zhao Q, He W, An F, Jiang L, Guo H (2012) Activation of ethylene signaling is mediated by nuclear translocation of the cleaved EIN2 carboxyl terminus. Cell Res 22:16131616Central

78. Wilkinson S, Davies WJ (2009) Ozone suppresses soil drying- and abscisic acid (ABA)-induced stomatal closure via an ethylene-dependent mechanism. Plant Cell Environ 32:949-959

79. Wilson RL, Kim H, Bakshi A, Binder BM (2014) The ethylene receptors ETHYLENE RESPONSE1 and ETHYLENE RESPONSE2 have contrasting roles in seed germination of Arabidopsis during salt stress. Plant Physiol 165:1353-1366Central

80. Wu L, Zhang Z, Zhang H, Wang XC, Huang R (2008) Transcriptional modulation of ethylene response factor protein JERF3 in the oxidative stress response enhances tolerance of tobacco seedlings to salt, drought, and freezing. Plant Physiol 148:1953-1963Central

81. Xia XJ, Zhou YH, Shi K, Zhou J, Foyer CH, Yu JQ (2015) Interplay between reactive oxygen species and hormones in the control of plant development and stress tolerance. J Exp Bot 66:2839-2856

82. Xiong L, Lee Bh, Ishitani M, Lee H, Zhang C, Zhu JK (2001) FIERY1 encoding an inositol polyphosphate 1-phosphatase is a negative regulator of abscisic acid and stress signaling in Arabidopsis. Genes 15:1971-1984

83. Xu H, Liu Q, Yao T, Fu X (2014) Shedding light on integrative GA signaling. Curr Opin Plant Biol 21:89-95 
84. Yang Q, Chen ZZ, Zhou XF, Yin HB, Li X, Xin XF, Hong XH, Zhu JK, Gong Z (2009) Overexpression of SOS (salt overly sensitive) genes increases salt tolerance in transgenic Arabidopsis. Mol Plant 2:22-31

85. Yang L, Zu YG, Tang ZH (2013) Ethylene improves Arabidopsis salt tolerance mainly via retaining $\mathrm{K}^{+}$in shoots and roots rather than decreasing tissue $\mathrm{Na}^{+}$content. Environ Exp Bot 86:60-69

86. Yang C, Ma B, He SJ, Xiong Q, Duan KX, Yin CC, Chen H, Lu X, Chen SY, Zhang JS (2015) MAOHUZI6/ETHYLENE INSENSITIVE3-LIKE1 and ETHYLENE INSENSITIVE3-LIKE2 regulate ethylene response of roots and coleoptiles and negatively affect salt tolerance in rice. Plant Physiol 169:148-165 $\underline{\text { Central }}$

87. Zhang H, Huang Z, Xie B, Chen Q, Tian X, Zhang X, Zhang H, Lu X, Huang D, Huang R (2004) The ethylene-, jasmonate-, abscisic acid- and $\mathrm{NaCl}$-responsive tomato transcription factor JERF1 modulates expression of GCC box-containing genes and salt tolerance in tobacco. Planta 220:262-270

88. Zhang F, Wang Y, Yang Y, Wu H, Wang D, Liu J (2007) Involvement of hydrogen peroxide and nitric oxide in salt resistance in the calluses from Populus euphratica. Plant Cell Environ 30:775-785

89. Zhang L, Li ZF, Quan RD, Li GJ, Wang RG, Huang RF (2011) An AP2 domain-containing gene, ESE1, targeted by the ethylene signaling component EIN3 is important for the salt response in Arabidopsis. Plant Physiol 157:854-865Central

90. Zhao Q, Guo HW (2011) Paradigms and paradox in the ethylene signaling pathway and interaction network. Mol Plant 4:626-634

91. Zheng Y, Zhu Z (2016) Relaying the ethylene signal: new roles for EIN2. Trends Plant Sci 21:2-4

92. Zhou H, Lin H, Chen S, Becker K, Yang Y, Zhao J, Kudla J, Schumaker KS, Guo Y (2015) Inhibition of the Arabidopsis salt overly sensitive pathway by 14-3-3 proteins. Plant Cell 26:1166-1182

93. Zhu JK (2002) Salt and drought stress signal transduction in plants. Annu Rev Plant Biol 53:247273 Central

94. Zhu JK (2003) Regulation of ion homeostasis under salt stress. Curr Opin Plant Biol 6:441-445 